\title{
Los confines de la representación. Figuraciones sobre el pasado brasileño a la luz del concepto de "heterogeneidad" de Ernesto Laclau
}

\section{Artículo de reflexión}

\section{Federico Eduardo Urtubey}

Universidad Nacional de La Plata, Argentina ue.federico@gmail.com

Recibido: 20 de julio de 2017

Aprobado: 10 de octubre de 2017

Cómo citar este artículo: Urtubey, Federico Eduardo (2018) Los confines de la representación. Figuraciones sobre el pasado brasileño a la luz del concepto de "heterogeneidad" de Ernesto Laclau. Calle14: revista de investigación en el campo del arte, 13 (23) pp. 158-169. DOI: https://doi.org/10.14483/21450706.12996

Este artículo se vincula con la línea de investigación sobre estética y política en la que tiene asidero mi beca doctoral, financiada por la Universidad Nacional de la Plata (UNLP), para el período 2015-2018. De igual forma, este trabajo involucra cuestiones elaboradas en la monografía final para la obtención del Diploma en Cultura Brasileña de la Universidad de San Andrés en el año 2016 (Buenos Aires, Argentina). 


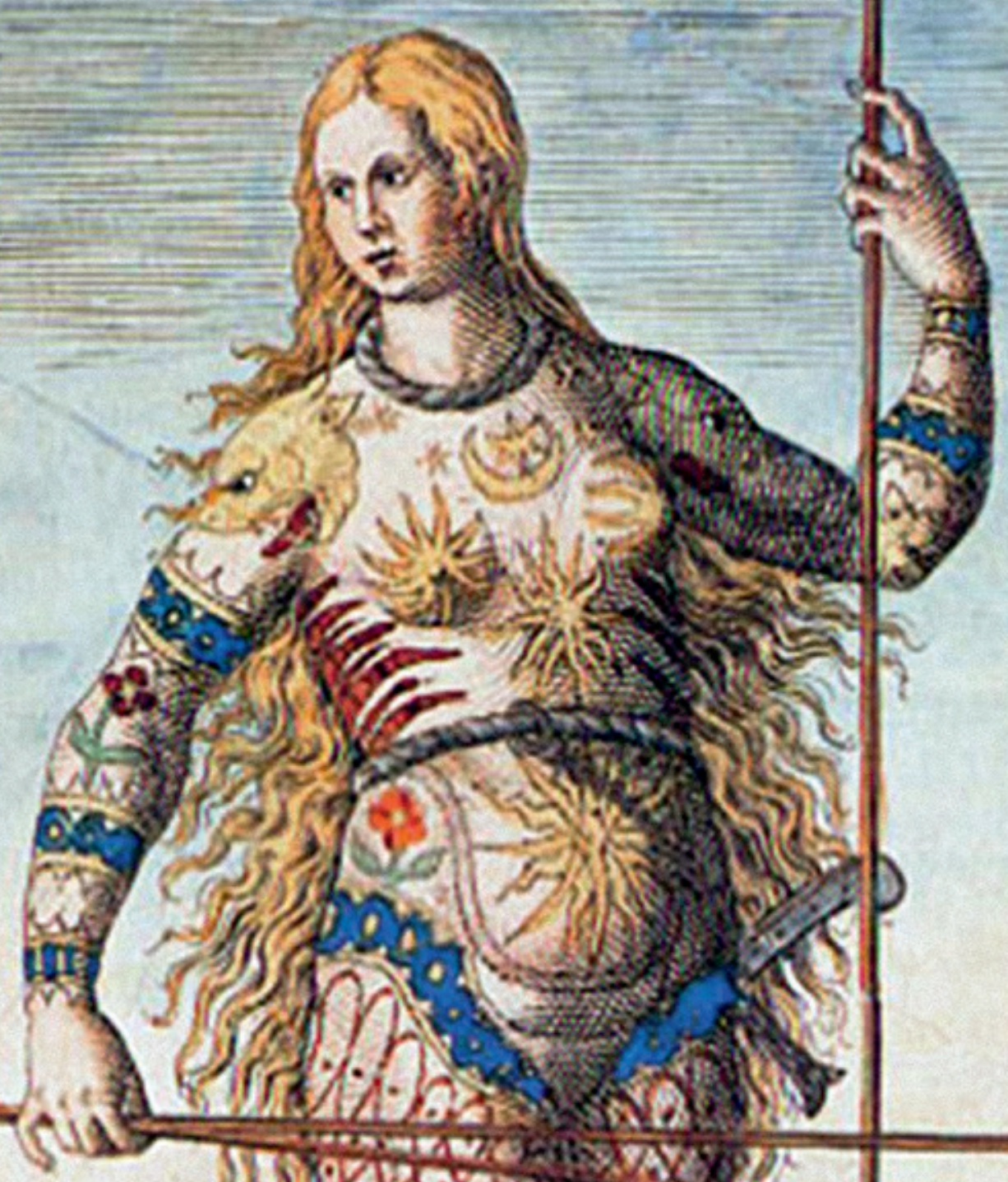

(1)

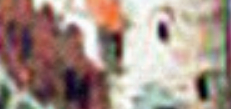
Pois:

3

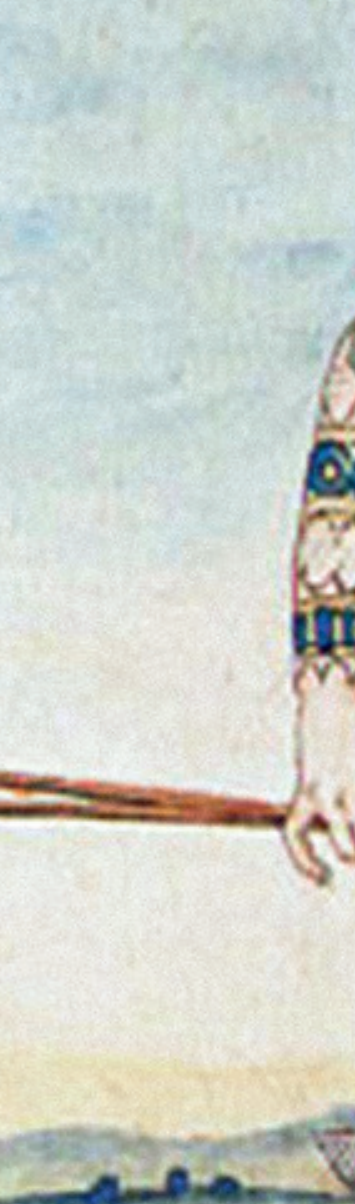

and $m$ m

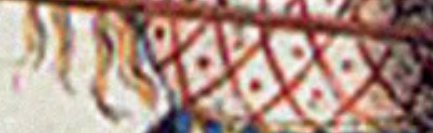
ain 1 sis

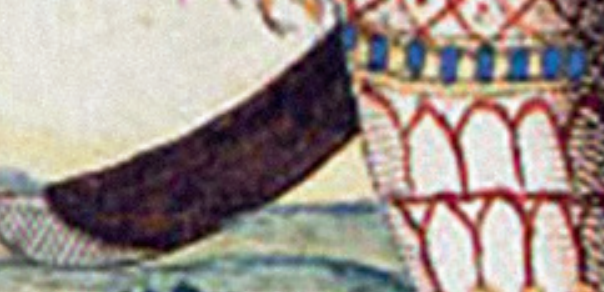

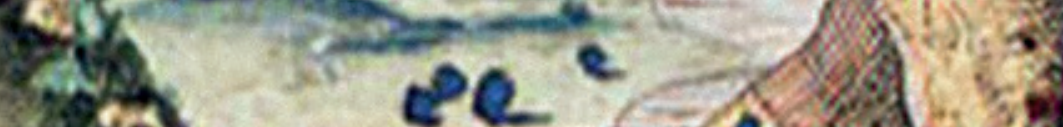
35
25

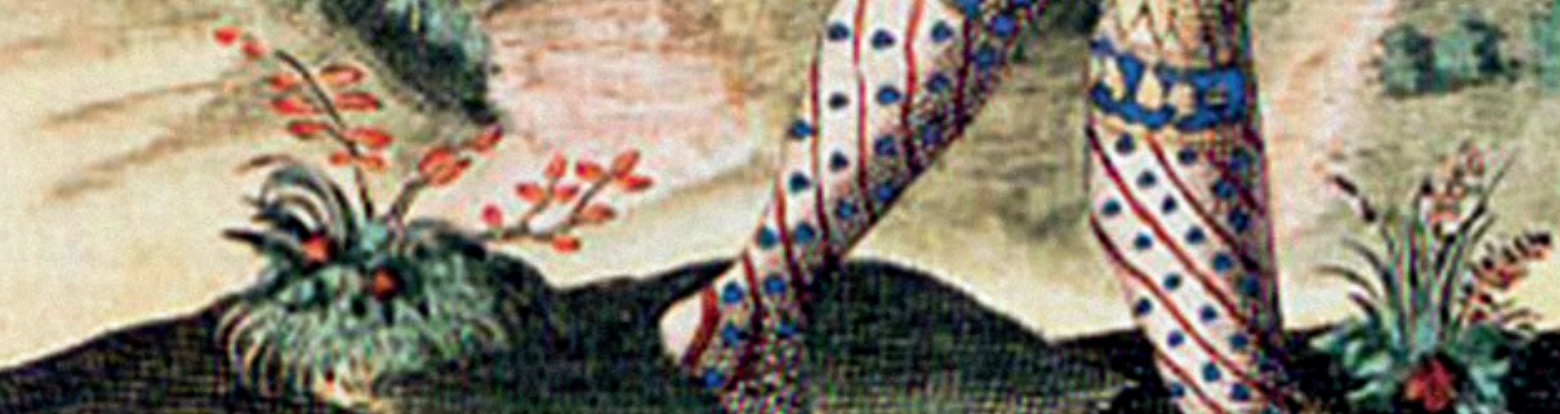

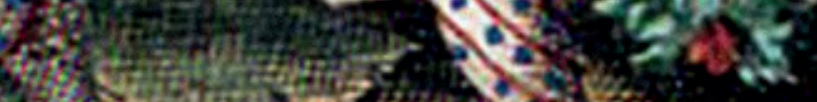
25:

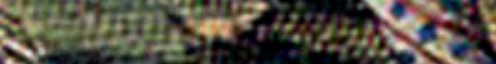
$42 y^{2}$ $2005 \times 40$ Tis

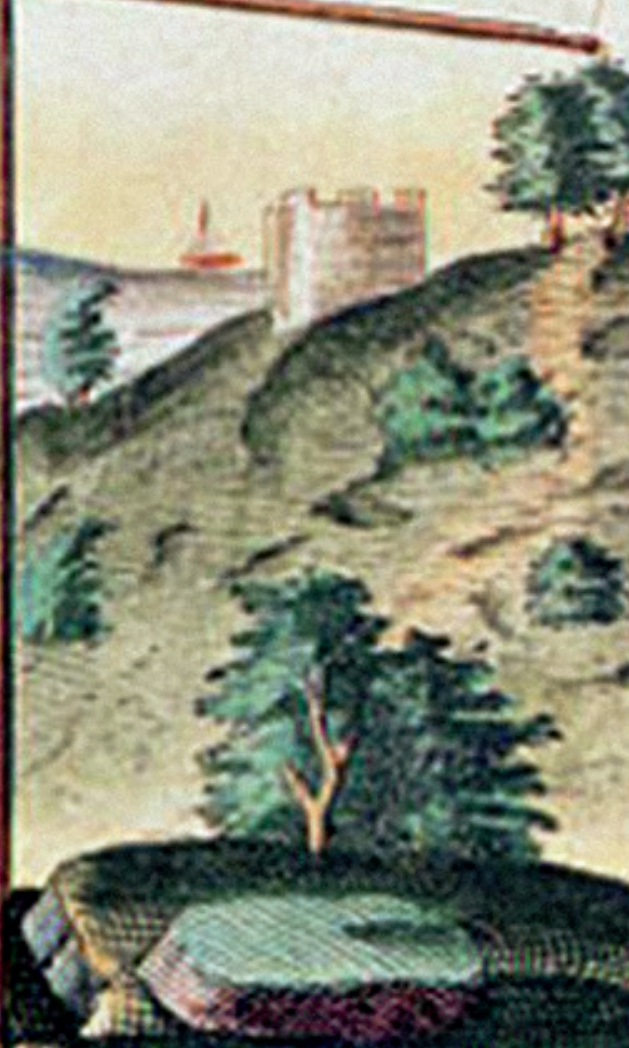

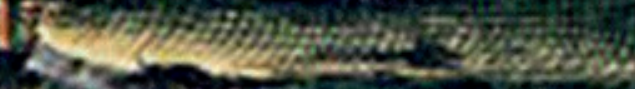


Los confines de la representación. Figuraciones sobre el pasado brasileño a la luz del concepto de heterogeneidad de Ernesto Laclau

\begin{abstract}
Resumen
El presente trabaja analiza una serie de producciones artísticas brasileñas a la luz del concepto de heterogeneidad. Dicho concepto, retomado desde la perspectiva del teórico Ernesto Laclau, permite avanzar en el estudio de las identidades sociales, y más aún, de las dificultades inherentes a la representación de aquello que resiste ser simbolizado. Nuestra hipótesis sostiene al concepto de heterogeneidad como una clave de lectura posible para algunas producciones culturales brasileñas de la actualidad. Se abordarán cuatro obras de la artista carioca Adriana Varejao, haciendo hincapié en las estrategias compositivas y procedimentales de las cuales se sirve la artista para tematizar cuestiones relacionadas con el orden colonial, el pasado histórico y la violencia. De esta manera, proponemos un análisis de obra desde la perspectiva de las ciencias sociales, articulándolo en discusiones más amplias vinculadas con los problemas de la representación.
\end{abstract}

\title{
Palabras claves
}

Heterogeneidad, Ernesto Laclau, Adriana Varejao, Brasil, Ciencias Sociales.

The confines of representation. Figurations about the brazilian past in light of Ernesto Laclau's concept of heterogeneity

\begin{abstract}
The present article analyzes a series of Brazilian artistic productions in light of the concept of heterogeneity. This concept, taken from the perspective of the theoretician Ernesto Laclau, allows to advance in the study of social identities, and even more, of the inherent difficulties in the representation of what resists being symbolized. Our hypothesis supports the concept of heterogeneity as a possible reading key for some Brazilian cultural productions of today. Four works by the Adriana Varejao artist from Rio de Janeiro will be addressed, emphasizing the compositional and procedural strategies that the artist uses to thematize issues related to the colonial order, the historical past and violence. In this way, the work proposes a work analysis from the perspective of the social sciences, articulating it in broader discussions linked to the problems of representation.
\end{abstract}

\section{Keywords}

Heterogeneity, Ernesto Laclau, Adriana Varejao, Brazil, social sciences.

Les limites de la représentation. Figurations sur le passé brésilien à la lumière du concept d'hétérogénéité d'Ernesto Laclau

\section{Résumé}

Le présent article analyse une série de productions artistiques brésiliennes à la lumière du concept d'hétérogénéité. Ce concept, pris du point de vue du théoricien Ernesto Laclau, permet d'avancer dans l'étude des identités sociales, et plus encore, des difficultés inhérentes à la représentation de ce qui se résiste à être symbolisé. Notre hypothèse soutient le concept d'hétérogénéité en tant que clé de lecture possible pour certaines productions culturelles brésiliennes d'aujourd'hui. Quatre œuvres de l'artiste Adriana Varejao de Rio de Janeiro seront abordées, en mettant l'accent sur les stratégies de composition et de procédure que l'artiste utilise pour thématiser les questions liées à l'ordre colonial, le passé historique et la violence. De cette manière, on propose une analyse de l'œuvre du point de vue des sciences sociales, en l'articulant dans des discussions plus larges liées aux problèmes de la représentation.

\section{Mots clés}

Hétérogénéité, Ernesto Laclau, Adriana Varejao, Brésil, sciences sociales. 
Os limites da representação. Figurações sobre o passado brasileiro à luz do conceito

de heterogeneidade de Ernesto Laclau

\section{Resumo}

O presente artigo analisa uma série de produções artísticas brasileiras à luz do conceito de heterogeneidade. Este conceito, tomado da perspectiva do teórico Ernesto Laclau, introduz no estudo das identidades sociais, e ainda mais, das dificuldades inerentes à representação do que resiste a ser simb olizado. Nossa hipótese apóia o conceito de heterogeneidade como uma possível chave para algumas produções culturais brasileiras de hoje. Serão abordadas quatro obras da artista Adriana Varejao do Rio de Janeiro, enfatizando as estratégias composicionais e processuais que a artista usa para lidar com questões relacionadas à ordem colonial, ao passado histórico e à violência. Desta forma, o trabalho propõe uma análise de a obra a partir das perspectivas das ciências sociais, articulando-a em discussões mais amplas ligadas aos problemas da representação.

\section{Palavras chaves}

Heterogeneidade, Ernesto Laclau, Adriana Varejao, Brasil, ciências sociais.

Ña puchukangapa kawachirriska, antiwamanda kawachiska kai Brasileñomanda i rimai sugmanda kai runa suti Ernesto Laclau

\section{Maillallachiska:}

Kai tsabajukuna kawachimi kai llunchiska pangapi sug Brasilmanda sugkunamanda kagkuna. Chasa rimaspa kaiarimmi rurai kai kilaikuna kai suti runa Ernesto Laclau, chasa iachaikuipi kawachimi maimandapi kagtakuna, i chasa iapa mana chasa kaskasina kai kawachingapa. Kai rimagsina charirimi sugrigchasina kagsina chasa kasa kai kilkaska iangapa kami iapachaia kai Brasilmanda kai punchakuna kaskauramanda. Kai ruraikunapi kami chusku Achka ruraskapi i situ, sug runa Carioca Adriana Varejao, chasa suma llugsispa ruraskata ñugpapa llugsichingapa kai ruraskata, ña Ialiska parlu kaurapi kaskami i sug iapa iakichinkunapi. Chasa kaura, iuichirimi sug iuiarii i kawai maipi kankunaiatata, i sug rimanakuspa iapa achaka rimai tiskapi i chasaiatata mana pasisiai tiaskapi.

\section{Rimangapa Ministidukuna:}

Heterogeneidad, Ernesto Laclau, Adriana Varejao, Brasilmanda, Ciencias Sociales. 


\section{Introducción}

El presente trabajo permite hacer uso de algunas cuestiones de la filosofía y teoría políticas hacia el interior de una crítica cultural o sociología de la cultura. Lo dicho implica abrevar, en parte, en aquellas perspectivas que entienden a la estética no como una esfera desvinculada de otras partes de lo social, sino, por el contrario, partícipe de la "distribución de lo sensible" y en tal aspecto emparentada con el campo de la política (Ranciere, 2013). De tal forma, en el presente trabajo se propone indagar en torno a una parte de la obra del teórico argentino Ernesto Laclau que, aunque no formuló lineamientos para pensar cuestiones estéticas, abre la puerta para pensar la naturaleza política de la disputa por la producción de sentido (Laclau y Mouffe, 2004). En el mismo sentido, es Chantal Mouffe quien recientemente se ha abocado al rol de las prácticas artísticas en la deconstrucción de los imaginarios sociales y el cuestionamiento de lo instituido, aseverando que "como sostuvimos Ernesto Laclau y yo en Hegemonía y estrategia socialista, una política democrática radical requiere la articulación de diferentes niveles de lucha, a fin de crear entre ellos una cadena de equivalencia" (Mouffe, 2014:105) para afirmar luego que "las prácticas artísticas y culturales pueden ofrecer espacios de resistencia que socaven el imaginario social necesario para la reproducción capitalista" (Mouffe, 2014:95).

En este orden de ideas el presente trabajo se propone analizar algunas producciones artísticas de la brasileña Adriana Varejao, para examinar de qué manera dialogan con problemáticas vinculadas con la tematización del pasado y su representación. Para ello, se partirá del análisis de la categoría laclaudiana de heterogeneidad. Nuestra hipótesis es que la misma puede erigirse como una clave de lectura posible, capaz de otorgar un marco interpretativo común al conjunto de elementos y figuras presentes en las obras.

\section{Discusión. El concepto de heterogeneidad}

Ernesto Laclau (1935-2014) es considerado uno de los máximos exponentes del pensamiento político posmarxista y el análisis político del discurso. Arraigado en una concepción post estructuralista y post fundacional, deben señalarse en este autor no sólo la redefinición del concepto de "hegemonía" formulado por Gramsci, sino también la influencia del posestructuralismo lacaniano. Esto último, particularmente en lo relativo a señalar al discurso -en un sentido amplio - como la fuente en torno a la cual se estructuran las identidades sociales. Esta perspectiva, eminentemente relacional, implica en Laclau el pensar a la hegemonía como la operación por la cual una particularidad asume la representación de una totalidad (Laclau, 2013: 95). Ello, "requiere admitir la naturaleza hegemónica de todos los tipos de orden social y el hecho de que toda sociedad es el producto de una serie de prácticas que intentan establecer orden en un contexto de contingencia" (Mouffe, 2011: 24). Esta perspectiva, según la cual "Lo social no es tan sólo el infinito juego de las diferencias, es también el intento de limitar este juego, de domesticar la infinitud, de abarcarla dentro de la finitud de un orden" (Laclau, 1993), permite afirmar que la articulación de un orden involucra "dar lugar a la existencia de ese objeto fallido que es la sociedad. No obstante, esta siempre conducirá al fracaso en tanto lo social es imposible de representar en la sociedad, hay un exceso de sentido que se resiste a ser completamente ordenado. Esto implica la existencia permanente de algo que queda al menos parcialmente por fuera de esa forma instituida..." (Retamozo, 2009: 80).

La heterogeneidad ha sido pensada como una categoría dúctil en el pensamiento de la crítica cultural latinoamericana. Autores como Nelly Richard o Néstor García Canclini se han apropiado de este término para describir la cultura latinoamericana. Canclini, en su clásico libro Culturas híbridas (1990) se ha referido a la "heterogeneidad multitemporal" aludiendo a las múltiples temporalidades históricas y condiciones socio económicas específicas que conviven en las distintas naciones latinoamericanas, sin concebirlas como etapas atrasadas en la convergencia hacia la modernidad. De este modo, la heterogeneidad multitemporal intenta poseer un cariz tanto antropológico como sociológico, capaz de echar luz sobre las diversas construcciones que los latinoamericanos han encaminado de cara al influjo de la Modernidad. En esa dirección, Nelly Richard entiende que, en el lugar de la periferia latinoamericana, los distintos patrones y modelos "son también generadores de heterogeneidad (de diversidad y multiplicidad) en la medida en que descomponen el imaginario previamente estratificado (...) para desplegar una creatividad casi enteramente basada en el reempleo de materiales preexistentes" (Richard,1989: 46-47).

Pero ya en el caso de Ernesto Laclau, la heterogeneidad es conceptualizada desde una perspectiva que escapa al sentido lato que se le ha otorgado. Así, expone en La Razón Populista (2013[2005]), que se 
ha servido de algunos desarrollos en torno al mismo, formulados anteriormente por Georges Bataille. En su análisis sobre el fascismo, Bataille (1931) parte de una oposición entre lo homogéneo —que sería el orden social-y lo heterogéneo - aquello que está fuera del orden- entendiendo que entre ambas instancias hay una mediación dialéctica. Lo homogéneo, entonces, indica lo calculable y lo cuantificable del orden social, es decir, la medida de lo instituido y que al mismo tiempo verifica la regularidad de las normas, la sujeción hacia lo previsible. En contraposición a ello, lo heterogéneo no podría ser asimilado por el orden, poseyendo una positividad propia.

Asimismo, Bataille distingue dos tipos de heterogeneidad: la impura, que será aquella en la cual puede designarse al proletariado, lo impuro, lo innoble, lo marginal y que queda ubicada por fuera del orden social, y la imperativa que es aquella que, no pudiendo ser asimilada por el orden social, puede potencialmente adquirir una supremacía por sobre dicho orden. Del mismo modo, es funcional a la homogeneidad, ya que los elementos discordantes de la heterogeneidad pueden articularse en una unidad que los hace ser algo diferente de sí mismos. Bataille utiliza este modelo para explicar el fascismo y el militarismo, ya que así extiende una explicación respecto de cómo los desclasados o los marginales pueden sujetarse a una discursividad que los regule y los conduzca.

Pero en Laclau la heterogeneidad, importante en lo relativo a la cuestión de la política y la representación, busca superar el binarismo. El autor se sitúa en la corriente pos fundacional que postula el debilitamiento ontológico de los fundamentos, lo que "(...) implica la creciente conciencia, por un lado, de la contingencia, y por el otro, de lo político como el momento de un fundar parcial y, en definitiva, siempre fallido" (Marchart, 2009:15). De este modo, ninguna representación podrá escapar a su naturaleza contingente, solo una posibilidad en el campo de lo indecidible.

De esta manera, en la perspectiva de Laclau el momento de lo político implicará siempre el establecimiento de una frontera antagónica que posibilite la construcción de un nosotros versus ellos. Ahora bien, Laclau esboza el concepto de heterogeneidad para aludir a aquello que está aún por fuera de esa dicotomía antagónica, como si fuese un resto que no tiene nombre ni puede ser simbolizado y que, al mismo tiempo, señala los límites y el carácter fragmentario de toda representación.
Lo heterogéneo carece de toda adscripción social. Si la política en Laclau es una actividad que en sí misma implica el discernimiento de un antagonismo capaz de distinguir un nosotros de un ellos, lo heterogéneo toma el lugar de aquello que no forma parte del ordenamiento simbólico. De este modo, lo heterogéneo impone una ruptura más radical que la del antagonismo, en tanto "presupone no sólo una exterioridad a algo dentro de un espacio de representación, sino respecto del espacio de representación como tal" (Laclau, 2013:176). Es por ello que Laclau rastrea lo heterogéneo como los pueblos sin historia en Hegel, o lo real en Lacan. En el caso de Marx, es teorizado como el "lumpenproletariado", es decir, aquella masa que queda ubicada por fuera del orden social. Así, desde la teoría marxista, ya por fuera de la oposición entre burguesía y proletariado, el lumpen-proletariado asume el lugar marginal de lo social, de escoria, de resto de la historia imposible de ser integrado en el modelo dialéctico. Siendo que, en contra del relato marxista, el lumpen proletariado no solo no quedó relegado sino que no dejó de crecer, Laclau define una postura contraria a la pregonada por Marx. Lo heterogéneo, lejos de ser un resto, es una cerca que rodea los espacios de representación, así como es constitutivo de aquellas demandas que no pueden hallarse equivalentes con otras en virtud de sus particularismos. Es por esto que Laclau afirma que "la heterogeneidad habita en el corazón mismo de un espacio homogéneo" (192).

En este orden de ideas, Laclau también cita a Fanon, quien hace una lista del "lumpenaje", de las prostitutas, mendigos, ladrones, todos como parte de lo heterogéneo. Aunque lo cierto es que la característica que reviste la heterogeneidad, en tanto forma parte de lo irrepresentable, es su imposibilidad de ser prefijada en determinadas clases o agentes sociales. Implica en cierto punto retomar la distinción lacaniana de lo Real respecto de la realidad, donde esta última se despliega como una instancia de ordenamiento, de intento de sistematización, de la fractura que impone lo Real. Lo Real en Lacan, es aquello que escapa a la representación y que, no pudiendo ser aprehendido, "provocará el insistente trabajo del inconsciente para simbolizarlo" (Shejtman, 2003:215).

Nuestra hipótesis apunta a relevar estas consideraciones tomando como objeto algunas obras de Adriana Varejao, una de las artistas brasileñas más reconocidas en la actualidad. Si la cuestión de la heterogeneidad se relaciona con la identidad, los contactos culturales y la condición fronteriza de todo discurso, es pertinente 


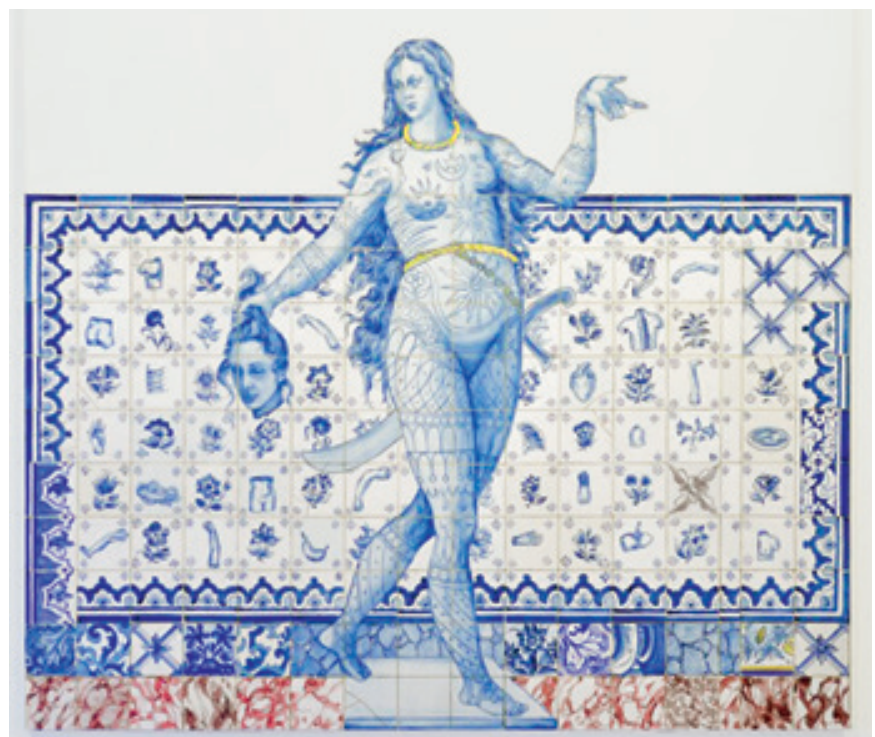

Adriana Varejão. Figura de convite II, 1998. Óleo sobre tela, 200 × 200 cm. Serie: Proposta para uma catequese.

analizar el funcionamiento de estas dimensiones en un territorio como el artístico.

\section{Cuerpo, paredes, historia}

Adriana Varejão (1973) es una de las artistas brasileras contemporáneas con más presencia en el circuito internacional del arte. Desde su primera exposición individual en el año 1988 hasta muestras más retrospectivas como la realizada en 2013 en el MALBA (Buenos Aires) su obra comenzó progresivamente a integrar el acervo de reconocidas instituciones como el MoMa, la Fundación Cartier y la galería Tate Modern. En todos los casos, si bien la producción de Varejão es profusa y abreva en diversos materiales y soportes, es posible reconocer una continuidad en el uso de elementos de fuertes reminiscencias de la tradición histórica. En muchos casos, estos se traducen en una apelación al imaginario de yugo colonial, del canibalismo y la antropofagia, de la misma manera que se invocan la geometría, el espacio arquitectónico y el diseño. El resultado de ello es un vocabulario plástico reconocible, aun en las distintas series en las que se desdobla el trabajo de la artista.

En el presente trabajo se propone el análisis de las obras "Lingua com padrao sinuoso" y "Parede como incisoes a Fontana", perteneciente a la serie Linguas e cortes, y "Figura de Convite" y "Varal", de la serie Proposta para uma catequese.

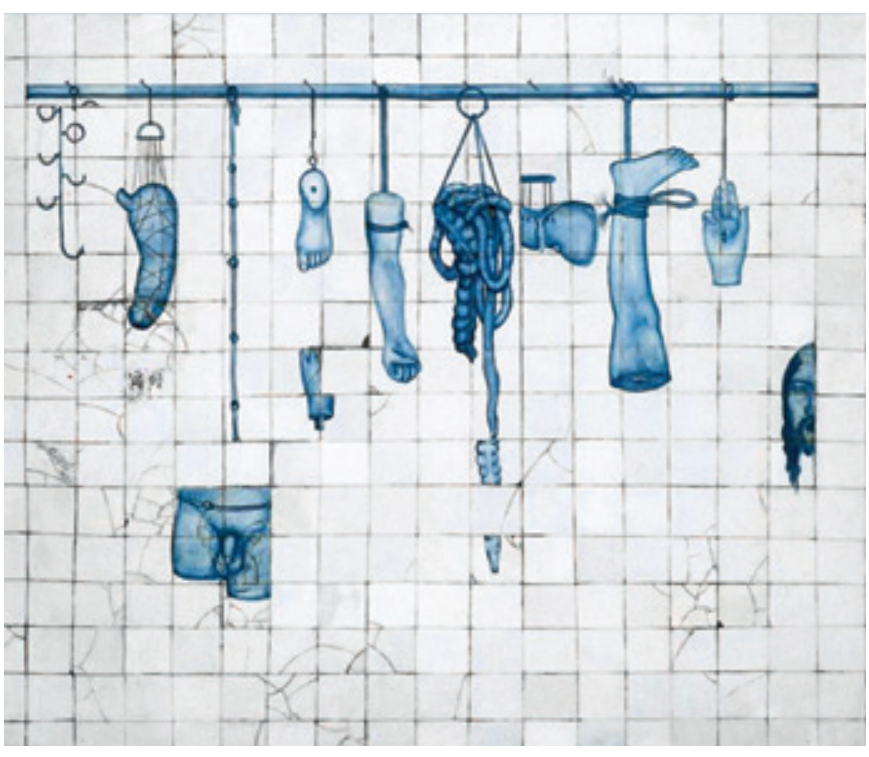

Adriana Varejão. Varal, 1993. Óleo sobre tela,165 x 195 cm. Serie: Proposta para uma catequese.

En una entrevista Adriana Varejão ha manifestado que su intención no es trabajar sobre un período histórico determinado, sino apropiarse de las etapas formativas de la cultura brasilera como un modo de reflexionar sobre el presente (Varejão, en entrevista ante Helene Kelmachter, 2004). En sus obras suele primar el azulejo como el elemento que organiza compositivamente las imágenes y que permite ser vinculado con la cultura material de los siglos XVII y XVIII, durante los cuales el imperio luso desembarcó en tierras brasileñas. De este modo, Figura de Convite 2 y Varal son obras que se anclan en aquellos intercambios entre la metrópolis y la colonia.

"Figura de convite II" — figura de invitación — es una pintura cuya estructura, eminentemente iconográfica, replica las figuras azulejadas que cubrían las portadas de los edificios públicos y palacios, así como también baños o piscinas, cuya función era ponderar o referenciar el espacio en el que estaban situados. Las "figuras de invitación" podían consistir en escenas de lo cotidiano o en figuras alegóricas, realizadas siempre con la técnica azulejada, siguiendo una isovalencia tonal que no escapaba del azul o el celeste. Este tipo de procedimientos se vincula a los siglos XVII y XVIII cuando en Portugal el revestimiento de ambientes comenzó a ser una técnica que cobró preminencia sobre otras como los cuadros o las esculturas (Simoes Cerqueira, 2009: 1837). Desde finales del siglo XVII el puerto de Macau en Portugal comenzó a ser un efluente de cerámicas blancas y azules procedentes de China destinadas a monasterios, plazas e iglesias, así como algunos 
encargos también provenían incluso de los países bajos. Esta continuada circulación de la azulejería no tardó en extenderse a los intercambios que Brasil mantenía con la metrópolis imperial portuguesa.

En Figura de Convite II podemos encontrar la presencia de todos estos elementos, a lo que debe agregarse que Varejão recurre a grabados del artista holandés Theodor De Bry, y emula una reproducción con la técnica del óleo. Su operación básica consiste en construir un espacio de figura fondo que, si bien parece ser una réplica de una imagen tradicional, en verdad está mediada por una fuerte apropiación de la artista. Y es que Varejão combina el fondo de un grabado superponiendo una figura humana perteneciente a otro del mismo autor. La imagen resultante de una figura femenina sosteniendo una cabeza humana - aun en un espacio geométrico y racionalizado- parece direccionar la potencia alegórica a la que remite la morfología de la figura femenina, a reminiscencias del orden del canibalismo o la violencia del régimen colonial.

En la técnica de Varejão se privilegia la representación de los azulejos por la vía de la pintura, antes que por la utilización efectiva de ese material. La artista ha manifestado que se trata de una elección consciente con el fin de procurar un efecto paródico, un gesto ilusorio, lo cual se conecta con el estilo barroco que se caracteriza por recrear artificios e ilusiones ópticas destinadas a confundir al espectador.

En la obra Varal -tendedero- la misma retícula de azulejos organiza el campo plástico de la imagen, al tiempo que en el centro de la escena, desde el "tendedero", penden hilos y sogas que sujetan piernas, tripas, brazos, manos y cabezas. La intencionalidad parece ser la misma: sobre los azulejos, cuya tradición presume refinación y pulcritud, se esgrime una imagen marginal, opaca, ambivalente. En este caso, el título de tendedero aparenta ser una operación no despojada de ironía, en tanto un "varal" aquí no se enlaza con un bodegón o una naturaleza muerta, sino con cuerpos mutilados y desollados, colgados como si fuesen ropa o una suerte de accesorio.

Tanto en Varal como en Figura de Convite II, el estilo que propicia el ensamble de las figuras es el barroco. Como se sabe, el surgimiento del barroco está asociado al esplendor de las monarquías y al movimiento de contrarreforma de la Iglesia Católica, la cual se sirvió de las artes plásticas para comunicar de manera eficiente el esplendor de la Iglesia (Maravall, 1990).
Pero el barroco es también el estilo que visualizaba, aun en una sociedad fuertemente estratificada, un espacio hiperteatral, complejo, de ilusionismo. De este modo, al momento de referirse al tema Deleuze (1989) señaló al "pliegue" (de las representaciones de vestidos, ornamentos, cuerpos) como aquella unidad, inseparable de otras como aquella, que cristaliza la constante circulación y fluir de ideas y puntos de vista. Así, y siguiendo a Mabel Moraña, debe apuntarse que en América "la cultura barroca es (...) mucho más que el modelo que reproduce en ultramar, en versiones subalternas, los principios de orden y los mecanismos de celebración del Estado imperial. Debe ser vista, (...) vulnerable también a los efectos de las prácticas de apropiación y producción cultural del letrado criollo que redefine el alcance y funcionalidad de los modelos recibidos de acuerdo con sus propias urgencias y conflictos" (Moraña, 1995). En este orden, no resulta extraño que Lezama Lima, haciendo pie en el caso brasileño, señale a Aleijadinho —escultor e imaginero mineiro del siglo XVIII - como uno de los íconos de estos interjuegos y saltos posibilitados por el barroco, en tanto acuñó sobre el estilo europeo formas decididamente disruptivas y que obedecían a un uso diverso del vocabulario plástico y retórico específicamente barroco: "São as chispas da rebelião que, surgidas da grande lepra criadora do barroco nosso, estão nutridas na sua própria pureza, pelos bocados do verídico bosque americano" (Lezama Lima, 1988:106).

En el caso de Adriana Varejão, consideramos que su uso del barroco intenta recorrer estos lineamientos que hemos señalado, en tanto es utilizado como un elemento compositivo más, conducente a reforzar la utilización paródica o irónica del alfabeto visual barroco. Tanto en el caso de Figura de Convite 2 como en Varal, la proximidad tonal entre la figura y el fondo permite composiciones envolventes y armónicas. Sin embargo, la mano que en una ocasión sostiene una cabeza de un cuerpo femenino, o bien el tendedero del cual cuelgan partes de cuerpos humanos y animalescos, permiten entender que estos motivos pertenecen tanto al mundo ilusorio y pulcro en el cual están incrustados, como participan de un mundo profano, violento, fronterizo.

En la serie Linguas e cortes, nuevamente los azulejos pueblan el fondo de la imagen, aunque la estrategia no parece ser ya jugar con una escena iconográfica, sino operar a través de la emulación de "incisiones" o aberturas del campo plástico. De este modo, irrumpen en la imagen otras materialidades que parecen brotar de las extremidades del campo plástico. 


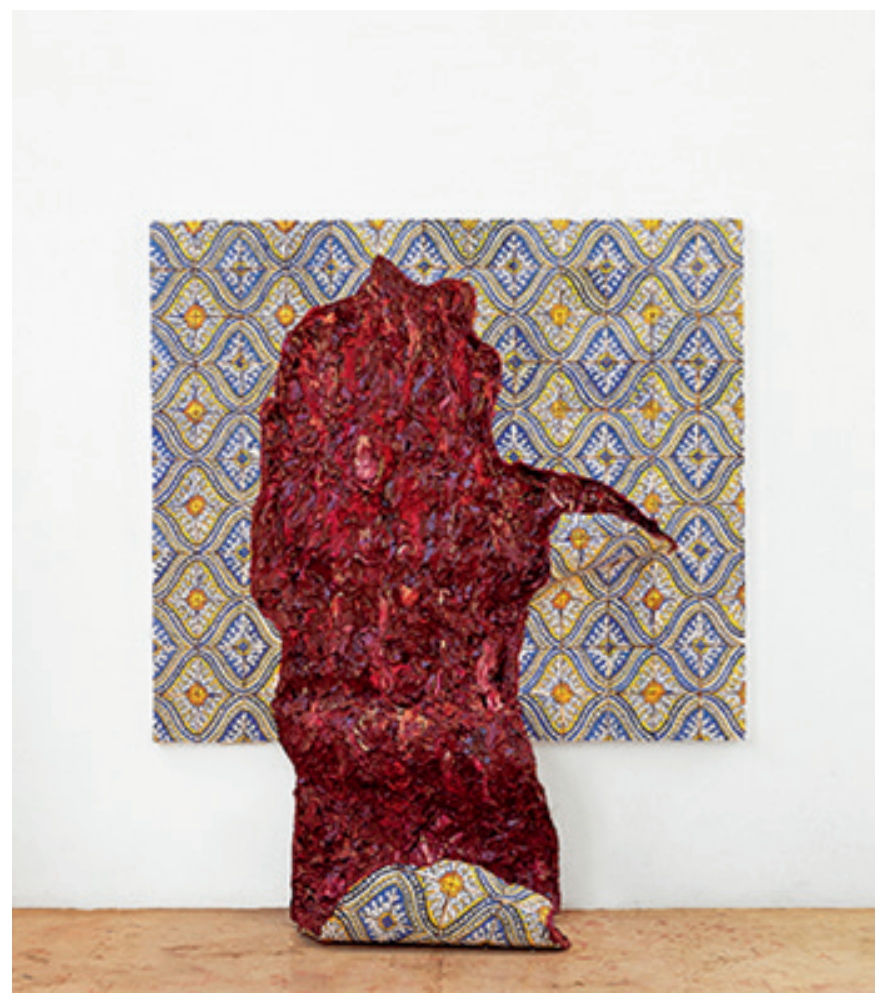

Adriana Varejão. Língua com padrão sinuoso, 1998. Óleo sobre tela e poliuetano em suporte de madeira e alumínio, $200 \times 170 \times 57 \mathrm{~cm}$. Serie: Linguas e cortes.

En "Lingua com padroe sinuoso", la "lengua" parece ser aquel conjunto de rojos, violetas y bermellones que recrean una gran masa de carne viva que se despega con facilidad de la retícula de azulejos, como si el peso de aquella lengua no tolerase ser solapado. De este modo, esa forma abierta rompe incluso el cuadrado de la imagen para llegar hasta el suelo.

El fondo, al igual que en las obras anteriores, consiste en un azulejado que en esta ocasión toma colores más diversos. No obstante, en la obra "Parede com incisoes a Fontana", los azulejos son blancos y recubren casi la totalidad del campo plástico. En esta obra, seis "incisiones" - siempre emuladas mediante la pinturapermiten apreciar que desde el "fondo" de la imagen, por detrás de la azulejería, existe la presencia de otra materialidad de colores vivos y carnosos. Quizás en este ejemplar es posible observar de manera patente cómo la pared de azulejos, que se aproxima a la figura de un muro por la pulcritud de los mismos, es jaqueada por la aparición de una materia inquietante que captura la mirada.

En este punto, Adriano Pedrosa ha señalado que tanto las representaciones de lenguas como la azulejería indican la "expressao de um colonialismo cultural tao sutil, por vezes imperceptível, porém duradouro: a decoracao" (Pedrosa, 1999: 2-5). En la representación de incisiones efectuadas, la aparición de masas de carne viva denuncian un interior desordenado y convulso, que al mismo tiempo impide distinguir, como también ha dicho este autor, entre figura y fondo.

Si bien la apropiación iconográfica que la autora realiza en la serie Proposta para uma catequese no tiene el mismo lugar en la serie Linguas e cortes, lo cierto es que Adriana Varejão ha manifestado que cuando piensa en la "carne" toma como referencia algunas pinturas de Rembrandt, Goya o Bacon (Varejão, en entrevista ante Helene Kelmachter, 2004). En paralelo con esos autores, la carne, así como los pliegues entre los cuerpos, se sitúa en los límites de lo putrefacto, lo abyecto, aquello que es objetivado, la mera carnalidad que ha perdido toda huella de sujeto. Como en el unheimliche freudiano, estos fragmentos de carne irrumpen inquietando el clima de las pinturas. Este concepto justamente permite indagar aquello que en el ámbito de lo familiar, lo cercano y lo conocido, de pronto es percibido como extraño o siniestro, es decir, alude a la manifestación de algo que debía permanecer oculto. La tesis freudiana de que "lo ominoso es aquella variedad de lo terrorífico que se remonta a lo consabido de antiguo, a lo familiar desde hace largo tiempo" (Freud, 1919: 1) permite entender esta serie de imágenes en las cuales, como en la serie Linguas e cortes, una fisura es oportunidad para revelar la contaminación de las formas, la convulsión de lo que parecía ordenado.

\section{Imágenes de lo heterogéneo}

Consideramos que la obra de Adriana Varejão puede proveer un horizonte más diverso si examinamos su obra a la luz del concepto de heterogeneidad. Tal cual lo hemos abordado, es posible enunciar una heterogeneidad más allá de su sentido lato —en tanto coexistencia de múltiples ordenamientos al modo de Canclini o Richard-, es decir, en su relación con lo que carece de un lugar propio.

De tal forma, es válido recordar que "lo heterogéneo irrepresentable, sin nombre, es el vacío en el que se da toda significación, es el espacio y dehiscencia que posibilita el movimiento rearticulatorio de toda narración (...) Un punto ciego en el texto mismo, inasible completamente, pero que por su ausencia posibilita que haya textualidad" (Groppo, 2010: 69). Así, en Linguas 


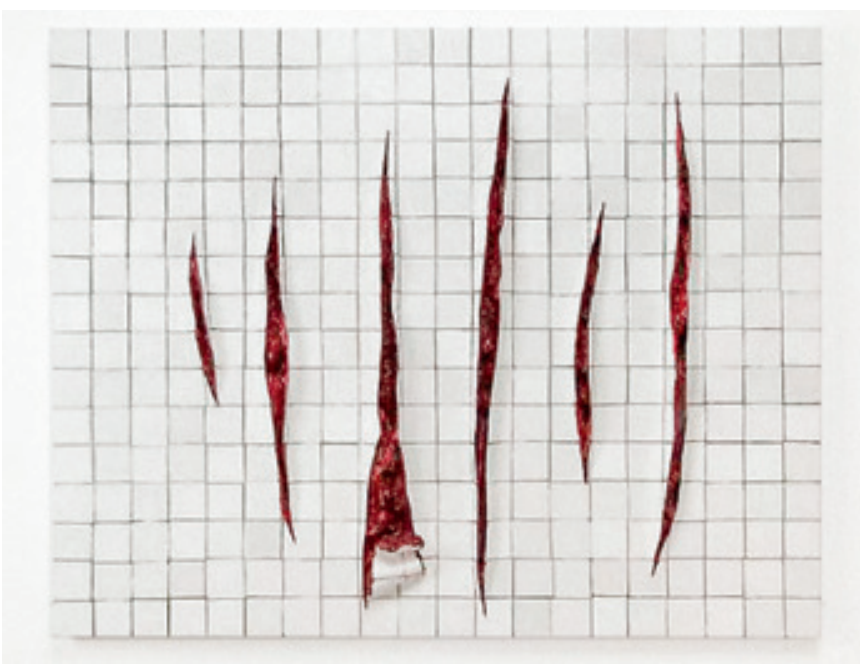

Adriana Varejão. Parede com incisões a la Fontana, 2000. Óleo sobre tela e poliuretano em suporte de alumínio e madeira,190 x $200 \mathrm{~cm}$. Serie: Linguas e cortes.

e cortes, por ejemplo, encontramos fragmentos de cuerpos y formas cavernosas imposibles de ser identificadas en una figura humana o varias. Mas bien, esas mezclas de carne y vísceras parecen desbordar las "incisiones", lo que habla de un tamaño descomunal o incontenible. Esta técnica de Varejao ciertamente propone la visualización de una escena de violencia y de opresión, sobre un otro que sin embargo aún no puede ser distinguido con claridad. De tal manera, si cuando Laclau citaba a Franz Fanon obteníamos una imagen de los colectivos de proletarios, prostitutas y mendigos que constituían una figuración de lo heterogéneo, en estas series de Varejão acontece algo similar. Ciertamente, las lenguas y los cortes parecen ser un montaje de relatos posibles sobre la violencia colonial, la conquista sobre los indígenas, el esclavismo negro.

Como ha señalado Simoes Cerqueira, "la carne representada da la ilusión de un cuerpo lacerado, con partes viscosas, ni líquidas ni sólidas, que no se refieren a un sujeto específico ni a un objeto, pero se sitúan en un lugar intermediario" (Cerqueira, 2009: 94, traducción propia). Tanto en Proposta para uma catequese como en Linguas e Cortes, es plausible observar una constante tensión entre espacio y forma, en la medida en que la frontera entre ambos se nos presenta como difusa. Ya sea por los detalles que alteran la pretendida invocación de un motivo iconográfico, como la representación de incisuras sobre el espacio plástico, lo cierto es que este tipo de obras parece estar sirviéndose de estas dimensiones para construir imágenes sinuosas, inestables. Entre los cerámicos y por debajo de los cortes, es posible observar la apertura de un espacio intermedio, que un receptor no demasiado avezado en la historia del Brasil fácilmente podría vincular con la imposición del orden por la fuerza. Las violencias múltiples, así como las resistencias, parecen ser metaforizadas en estas carnes revueltas que sacuden el orden continuo de la cerámica portuguesa. Así, "la realidad aguanta, soporta, sufre. $Y$ es que inesperadamente puede acontecer el encuentro con lo real... traumático, allí es donde la realidad desfallece. El trauma, el accidente, supone en la contingencia un desgarro de la realidad. Incluso, a veces, la pérdida de la realidad." (Shejtman, 2003: 217)

Este lugar intermedio que apareja la coexistencia entre dos órdenes parece continuar la fractura de lo Real, que en Lacan alude a un imposible lógico inaprensible, que todo el tiempo busca ser representado. Ya en el caso de obras como Figura de Convite 2, la cabeza decapitada que la mujer toma de la mano, más que aludir al acto de engullir a alguien, parece denotar el recorte de un acto de brutalidad en el marco de lo que parece ser una representación de una imagen de lo cotidiano. De la misma manera, la obra Varal muestra al estilo de una naturaleza muerta tejidos humanos sujetos a un cordel. Estas dos utilizaciones paródicas, siniestras, de la iconografía, echan luz sobre una operación recurrente en la obra de Varejão: representar la incompletitud del orden en el corazón del orden mismo. La aparición de elementos paródicos no implica otra cosa que la inevitable fractura de todo constructo material (y simbólico).

Los bordes, las fisuras y los pliegues por los cuales asoman de manera espectral corporalidades humanas, cuando no animalescas, son entonces la anunciación de una otredad que todavía no puede ser visualizada. La carencia de un nombre, es decir, el hecho de estar situado en los límites de la simbolización, no confirma sino la naturaleza porosa de toda estructura.

Estas obras entonces establecen el anuncio de formas y sujetos que resisten la integración simbólica, que se sitúan en los confines de la representación y por tanto están tan por fuera del orden que lo amenazan, pero al mismo tiempo son su condición de posibilidad. Los elementos que constituyen el repertorio de Varejão pueden ser involucrados con episodios específicos de la historia brasileña, del choque entre orden y subjetividad. Sea como fuere, este lenguaje plástico parece habitar un ámbito intersticial entre las interpretaciones posibles. Es por ello que hemos encontrado en la 
categoría de lo heterogéneo una clave de lectura afín, ya que en su espectro se comprende a los que están por fuera del campo político. Pero esa extranjería deviene "imposible determinar a priori quiénes van a ser los actores hegemónicos en esta lucha (...) Todo lo que sabemos es que van ser los que están fuera del sistema, los marginales -lo que hemos denominado lo heterogéneo- que son decisivos en el establecimiento de una frontera antagónica" (Laclau, 2005: 189).

En suma, si hemos entendido a lo heterogéneo como aquello que implica una ruptura del espacio de representación en tanto tal, es que podemos ubicar a las obras de Varejao como una tematización de ese constante acecho de algo que todavía no tiene forma o que no puede ser nombrado en tanto escapa de lo conocido (¿la negritud? ¿el pueblo? ¿los indígenas?) pero que indudablemente tiene una existencia.

\section{Conclusión}

Si bien Adriana Varejão ha manifestado que no pretende que su pintura referencie un período histórico en particular, como podría ser el colonial, su obra recurre a la caja de herramientas de la historia del arte como una dimensión más de las indagaciones sobre el presente.

Ya en torno a la cuestión de la heterogeneidad, debe afirmarse que sin perjuicio de la pertenencia de este concepto al campo de la teoría política, para la cual "la construcción del pueblo [es] el acto político par excellence" (Laclau, 2013: 195), es necesario señalar que el mismo ha sido sensiblemente redefinido de la mano de autores en principio ajenos a ella, como Bataille o Lacan. De ese modo, la cuestión de la heterogeneidad participa de un conjunto más amplio de reflexiones que se articulan como vasos comunicantes entre diversas disciplinas. De tal modo, la teoría política, la filosofía y el psicoanálisis se ven imbricados en la cuestión de cómo representar aquello de lo que aún no podemos dar cuenta cabalmente, lo que reconfigura tanto las fronteras de estudio de las prácticas culturales como la del objeto mismo del pensamiento político.

Si nuestra reflexión se orienta, como en este caso, a explorar la resolución de estas cuestiones hacia adentro de la cultura brasileña, la estética de Varejão, sus tensiones entre cuerpo y estructura, entre edificios coloniales y corporalidades desolladas, emergen como un discurso marginal que desacata los discursos del encuentro y la homogeneización. En ella, como hemos afirmado, la azulejería o la iconografía son estructuras que se ven atravesadas por cortes y fisuras, de las cuales emanan formas y motivos tétricos, sombríos, que quiebran el espacio y la temporalidad del campo plástico en el que irrumpen. Estos cruces interpelan al imaginario de la violencia en la vida cotidiana, así como a las tensiones del mundo colonial, importando el intento de dar cuenta de un tipo de des-acomodamiento, de fractura, donde toda representación (en este caso, de espacios suntuosos) lleva implícita su naturaleza contingente.

\section{Referencias}

Cerqueira, Fátima Nader Simões (2009). Memória e Persuasão na Pintura de Adriana Varejão. Tesis de Maestría en Artes. Centro de Artes - Universidade Federal do Espírito Santo. Disponible en: www.arpap. org.br Fecha de consulta:17/01/17.

Deleuze, Gilles (1989). El pliegue. Leibniz y el Barroco. Barcelona: Paidós.

Groppo, Alejandro (2010). “Heterogeneidad y política en Bataille y Laclau" en Studia Politicae, No. 20. Facultad de Ciencia Política y Relaciones Internacionales, UCA (Córdoba, Argentina) Disponible en: bibdigital.uccor. edu.ar Fecha de consulta: 5/02/17.

Haroldo de Campos: «De la razón antropofágica. Diálogo y diferencia en la cultura brasileña», Vuelta, № 68, junio de 1982, pp. 12-13. Disponible en: www.humanindex. unam.mx Fecha de consulta: 5-02-17.

Laclau, Ernesto (2013 [2005). La razón populista. Buenos Aires: Fondo de Cultura Económica.

Laclau, Ernesto (1993). Nuevas reflexiones sobre la revoIución de nuestro tiempo. Buenos Aires: Nueva visión.

Laclau, Ernesto y Chantal Mouffe (2004 [1985]). Hegemonía y estrategia socialista. Buenos Aires: Fondo de Cultura Económica.

Lezama Lima, José (1988). A expressão americana. Tradução de Irlemar Chiampi. São Paulo: Brasiliense.

Maravall, José Antonio (1990). La cultura del barroco. Barcelona:Ariel. 
Marchart, Oliver (2009). El pensamiento político posfundacional. La diferencia política en Nancy, Lefort, Badiou y Laclau. Buenos Aires: Fondo de Cultura Económica.

Moraña, Mabel (1998). Viaje al Silencio: Exploraciones del discurso barroco.México: Facultad de Filosofía y Letras. México: Universidad Autónoma de México.

Mouffe, Chantal (2014 [2013]). Agonística. Pensar el mundo políticamente. Buenos Aires: Fondo de Cultura Económica.

Mouffe, Chantal (2011 [2007]). En torno a lo político. Buenos Aires: Fondo de Cultura Económica.

Pedrosa, Adriano; Varejão, Adriana (1992) Trabalhos e referências 1992 - 99. São Paulo: Galeria Camargo Vilaça.

Ranciére, Jacques (2013 [2008]). El espectador emancipado. Buenos Aires: Manantial.

Retamozo, Martin (2009). "Lo político y la política: los sujetos políticos, conformación y disputa por el orden social", En: Revista Mexicana de Ciencias Políticas y Sociales, Vol. 51 No. 206, pp. 69-89. Disponible en: www.revistas.unam.mx Fecha de consulta: 17-01-17

Richard, Nelly (1989). La estratificación de los márgenes. Sobre arte, cultura y política/s. Santiago de Chile: Francisco Zegers Editor. Disponible en: www.centrodedocumentaciondelasartes.cl Fecha de consulta: 5-02-17

Shejtman, Fabian (2003). "Una introducción a los tres registros", en Mazzuca, R. (comp) Psicoanálisis y psiquiatría. Encuentros y desencuentros. Temas introductorios a la psicopatología. Buenos Aires: Eudeba.

Varejão, Adriana. Entrevista con Hélène Kelmachter. 2004. Disponible en: www.adrianavarejao.net.

Fecha de consulta: 17/01/17.

Williams, Raymond (2009). Marxismo y literatura.

Buenos Aires: Las Cuarenta. 